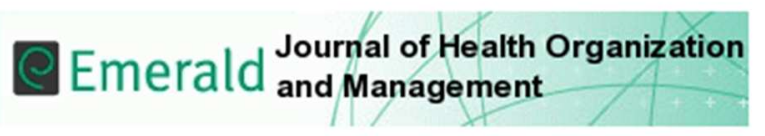

\title{
Improving care for people after stroke: how change was actively facilitated
}

\begin{tabular}{|r|l|}
\hline Journal: & Journal of Health Organization and Management \\
\hline Manuscript ID: & JHOM-May-2011-0053.R3 \\
\hline Manuscript Type: & Original Article \\
\hline Keywords: & Change, External facilitation, Stakeholder engagement \\
\hline \multicolumn{2}{|}{} \\
\hline
\end{tabular}

\section{SCHOLARONE ${ }^{\text {m }}$ \\ Manuscripts}


Manuscript ID JHOM-May-2011-0053.R3

Title: Improving care for people after stroke: how change was actively facilitated

\begin{abstract}
:
Purpose: This paper reports on the approach to change used in the development of a tool to assess patient status six months after stroke (the Greater Manchester Stroke Assessment Tool: GM-SAT).

Design/methodology/approach: The overall approach to change is based on the Promoting Action on Research Implementation in Health Services (PARiHS) Framework, which involves extensive stakeholder engagement before implementation. A key feature was the use of a facilitator without previous clinical experience.

Findings: The active process of change involved a range of stakeholders - commissioners, patients and professionals - as well as review of published research evidence. The result of this process was the creation of the GM-SAT.

Practical implications: The details of the decision processes within the tool included a range of perspectives; the process of localisation led commissioners to identify gaps in care provision as well as learning from others in terms of how services might be provided and organised. The facilitator role was key at all stages in bringing together the wide range of perspectives; the relatively neutral perceived status of the facilitator enabled resistance to change to be minimised.

Social implications: the output of this project, the GM-SAT, has the potential to significantly improve patients' physical, psychological and social outcomes and optimize their quality of life. This will be explored further in future phases of work.

Originality/value: A structured process of change which included multiple stakeholder involvement throughout, localisation of approaches and a dedicated independent facilitator role was effective in achieving the development of a useful tool (GM-SAT).
\end{abstract}

Keywords: change, external facilitation, stakeholder engagement

Paper classification: Case study (a 'work-in- progress' descriptive piece)

\title{
Introduction
}

Stroke is a common disease, with 110,000 new strokes in the UK per year. It is also expensive, costing $>£ 7 \mathrm{bn}$ annually in health and social care costs and is devastating for the individual and his or her family (National Audit Office, 2005). The National Health Service (NHS) faces some challenging targets set by the Department of Health in response to the National Stroke Strategy (Department of Health, 2007) and the Accelerated Stroke Improvement Programme (Accelerated Stroke Improvement Programme, 2010) in an attempt to radically improve care for people following a stroke. Particular emphasis is placed on 
Manuscript ID JHOM-May-2011-0053.R3

improving the long term care of people who suffer the sequelae of stroke often for many years. In order to implement new ways of managing any illness, the providers of care in the NHS and social services need to change the way in which they work. Providing and managing long term care following stroke is particularly challenging as it involves many different issues, and combinations of issues affecting individual patients and their multiple providers and systems of care.

Effecting change within health and social care is difficult. Central policy instructions requiring care providers to change are very unlikely to be effective, even if there is compelling evidence to support the change. Change has been a constant feature of the UK healthcare sector for many years and has affected every individual in the NHS at some point in their career, often on many occasions (Bamford \& Daniels, 2005). Unfortunately, many people come through the process of change feeling bruised, disenchanted and de-motivated. As a consequence the laudable aims of the change are all too often lost in the 'noise' of the process (Freeth, 2004). Ideas differ about implementing change but there is some agreement that change initiatives do fail (Aiken and Keller, 2009; Burnes, 2009; Bamford and Forrester, 2003). Focused modernization, performance targets and increases in funding have not delivered the transformation the UK government wanted to see in the NHS (Harvey et al, 2007), with cultural differences and professional allegiances recognized as major blocks to change (Truss et al, 2006; Deeter-Schmelz and Kennedy, 2003). There is a perception that NHS changes that were financially driven led sympathetic stakeholders to distrust the process (Farrington-Douglas and Brooks, 2007) but many organizations trusted financial incentives as the solution to every problem, including problems caused by financial incentives in the first place (Pfeffer and Sutton, 2006). Implementation of new strategies to improve care is therefore one of the greatest challenges faced by the NHS (Walker and Bamford, 2011). 
Manuscript ID JHOM-May-2011-0053.R3

\section{Objective}

This paper reports on the approach to change used in the development of a tool to assess patient status six months after stroke (the Greater Manchester Stroke Assessment Tool: GMSAT). The paper describes the way in which a new assessment tool to improve the long term management of people with stroke was developed. The change process utilised the facilitation skills of a non-clinician working as part of a multi-disciplinary team within a health economy; it was based around a series of steps with extensive stakeholder involvement.

\section{Background}

The resource for this work was provided by the National Institute of Health Research (NIHR) 'Collaboration for Leadership in Applied Health Research and Care' (CLAHRC) for Greater Manchester. Nine CLAHRCs were funded in England from October 2009 for five years and in Greater Manchester, the CLAHRC (http://clahrc-gm.nihr.ac.uk/) is a collaboration between the University of Manchester and NHS organisations, with funding coming from primary care and the University of Manchester as well as NIHR. The Greater Manchester CLARHC aims to improve healthcare and reduce inequalities in health for people with cardiovascular conditions (diabetes, heart disease, kidney disease and stroke) through carrying out research, putting it into practice (implementation) and building capacity in the NHS to do this.

Each theme of work within the CLAHRC involves a series of change initiatives that build on current evidence and national policy initiatives and works in partnership with, as appropriate, the research programmes within the CLAHRC. The specific focus for action is determined by a Clinical Lead with disease-specific expertise, in conjunction with key stakeholders from NHS primary, community and secondary care providers, commissioners and service users. 
Manuscript ID JHOM-May-2011-0053.R3

\section{Method}

The framework for change used is based on both the Model for Improvement (Langley et al, 2006) and the Promoting Action on Research Implementation in Health Services (PARiHS) framework, as detailed in Harvey et al (2011), and acknowledges that implementing change and getting research into practice may be regarded as a complex, messy and demanding task (Kitson et al., 2008; Rycroft-Malone et al., 2004). The framework starts with a process of stakeholder engagement that then leads to identification of the objective of the change, and how its impact will be measured. Suitable changes, supported by a robust evidence base about 'what' to do (where such exists) are then identified, implemented on a small scale using an incremental improvement approach (Plan-Do-Study-Act (PDSA) cycles) before spread and sustaining if the impact of the change is effective. The change management framework is underpinned by the acknowledgement that: i) the successful implementation of evidence requires whole system changes involving individuals and organisations; ii) such change is not a linear or technical process; iii) individuals are more likely to engage with and support change if they can see a strong need for it, are in an environment which supports it rather than hinders it and they have people to help (Walsh, 2005). The framework itself is based on "knowledge relating to the effectiveness of certain implementation strategies and interventions, i.e. evidence about implementation.” (Harvey et al, 2011:3). However, this acknowledges that as implementation progresses, the details of how the framework is used will vary in response to the context and the progress of the change process.

The change initiative reported in this paper was facilitated by a full-time member of staff (a 'Knowledge Transfer Associate' or KTA), who worked as part of a team which also included a Stroke Consultant and Business School academic, as well as staff from the NHS and other 
partner organisations. The KTA role has facilitation as one of its key elements, in line with the importance given in the PARiHS framework to the role of facilitation (Harvey et al, 2011)

\section{The need for change}

Over the past five years, great leaps have been made in the provision of high quality acute stroke services (National Audit Office, 2010). Many hospitals now provide thrombolysis (clot-busting treatment), rapid access to brain imaging services and specialist stroke units staffed by specialist clinicians. However, as highlighted in the National Audit Office's (NAO) 'Progress in improving stroke care' report (National Audit Office, 2010) these improvements in acute stroke care are not yet matched in delivering effective long term support and care to both stroke survivors and their carers. Over a third of stroke patients suffer from a mood disorder in the first year after stroke onset, eighteen percent have communication difficulties on discharge from hospital and many more experience problems such as fatigue, poor concentration and mobility problems. Further, many people report a sense of abandonment following discharge from hospital and community rehabilitation (Department of Health, 2007), and have difficulty accessing appropriate services.

The National Stroke Strategy (Department of Health, 2007) stipulates that all people with stroke and their carers should be offered a comprehensive review of their health needs 6 months following discharge from hospital, but it does not detail what the review should entail, who should undertake it, or what should be done with the information obtained. The requirement for a six month review is now (2011) part of the Accelerating Stroke Improvement Programme (Accelerated Stroke Improvement Programme, 2010) within which all NHS providers and commissioners will be measured on the percentage of people discharged from hospital who are offered a 6 month review. 
Manuscript ID JHOM-May-2011-0053.R3

\section{The Review Process}

In line with the framework for change (Harvey et al, 2011) a process of stakeholder engagement was undertaken in 2009 which drew on an informal review of local stroke services in Greater Manchester. This involved conversations with stakeholders, including stroke commissioners and clinical leads, and a review of available documents, such as local stroke strategies and joint strategic needs assessment reports. This revealed that, despite the national requirement and the need to report on this measure by April 2011, few localities had a post-stroke, follow-up review process in place. These results were confirmed by joint strategic needs assessments that several PCTs had undertaken in the preceding months. In areas where stroke reviews were being delivered, conversations with service managers and clinicians revealed that only a minority of patients were accessing the service. Furthermore, that the reviews focused solely on stroke secondary prevention rather than looking to identify and address the patients' wider health, social and emotional care needs. This left stroke survivors, in their own words, "left to swim alone against the tide". It was apparent that there was no consensus on what would constitute a 6 month stroke review; commissioners and providers alike were unclear as to what the review should consist of, what its objectives should be, who it should be led by and how it should be delivered. This led to the definition of objectives for a process of change to develop a post-stroke assessment tool and define its content (the Greater Manchester Stroke Assessment Tool: GM-SAT). It was also necessary to assess how GM-SAT could be implemented into routine practice across Greater Manchester to enable PCTs to meet the requirements of the Accelerating Stroke Improvement Programme. This addressed the question "What change can we make that will result in improvement?", an element of the Model for Improvement (Langley et al, 2006). In this case, 
the initial measure of impact was simply that the assessment takes place, in line with the Accelerating Stroke Improvement Programme.

\section{Action taken}

In developing the GM-SAT, the first step required was to identify the common long-term problems experienced by stroke survivors and their carers. GM-SAT aimed to amalgamate research-based knowledge with the tacit and experiential knowledge of stroke professionals, patients and their carers, to develop a review tool that was both evidence-based and contextualised.

Areas of common post-stroke problems were identified using several overlapping methods (Figure 1). Qualitative and quantitative literature describing long-term, post-stroke needs, including national policy and professional clinical guidelines, was identified and reviewed by the KTA to give a provisional list of areas to be covered. International research literature was identified through the PubMed database using key search terms such as post-stroke problems, long term care and post-stroke needs. This narrative review identified more than fifty common post-stroke problems spanning health, social and emotional care for consideration for inclusion within GM-SAT. In order to integrate this with local perspectives, the KTA organised and moderated four focus groups at which stroke survivors and their carers were asked to reflect and give an account of the long term problems they experienced after the stroke event, with particular emphasis placed on the problems that they encountered approximately six months after leaving hospital. Participants were recruited following a formal presentation about the project at a meeting of an existing local stroke club. In total, 52 stroke survivors and carers participated in this process. Formal ethical approval was not required for these focus groups, since they were classified by NHS governance procedures as 
Manuscript ID JHOM-May-2011-0053.R3

service evaluation but ethical principles were supported (participants signed a consent form agreeing to take part in the focus group, to be recorded, for the information they provided to be used for service analysis and improvement). The opinions of stroke professionals from across the multidisciplinary team, including those from local authority and third sector organisations, on what they considered to be the problems experienced by stroke survivors were obtained in a half day interactive workshop with 36 attendees.

"Take in Figure 1"

Many areas, such as depression (Hackett et al, 2005), continence (Jørgensen et al, 2005) and mobility (van de Port et al, 2006), were described in the international research literature. These areas were also identified by service users and stroke professionals, confirming the need to include them within GM-SAT. However, within the workshop and focus groups, several problem areas not in the literature were identified, including hyperacusis (increased sensitivity to noise), altered sleep pattern and problems relating to sexual health.

All of these problem areas, identified by service users and/or described in the literature, were reviewed by a group of expert stroke professionals who decided whether they should be included within GM-SAT. This core group consisted of eight clinicians, including a stroke physician, psychologist, rehabilitation therapy lead, with further experts including nurses, therapists and community stroke staff joining the group when their expert advice and views were required. The KTA actively co-ordinated and facilitated the collection and collation of the problem areas; this role was central to ensuring project success through providing someone with the role, responsibility and capacity to engage. In total 36 of the original problem areas identified were selected for inclusion in the GM-SAT (Table 1). These were 
taken back to, and checked by, several of the patients and carers from the initial focus groups who had indicated they were happy to be contacted again. This helped to ensure that no common problems had been overlooked.

\section{"Take in Table 1"}

This work ensured that a legitimate evidence base was developed, from the perspective of medical literature, patient and professional experience. From this data, simple management 'algorithms' were created for each of the problem areas. These served to embed evidencebased practice within the whole assessment process and to ensure that actions taken in response to each problem were also in-line with current best practice as identified by national clinical guidelines (Intercollegiate Stroke Working Party, 2008). The algorithms were flow diagrams to guide the person carrying out the review through the assessment process; from a set of simple closed questions through to an appropriate action, be that a referral, provision of information and advice or signposting to local services. Figure 2 provides an example of one such management algorithm. A multidisciplinary task-finish group of professionals from across the stroke pathway was established to develop the algorithms; 36 evidence-based algorithms were constructed over a four month period. Where an aspect of quantification was required, in response to a problem, then a validated assessment tool, such as the Malnutrition Universal Screening Tool (MUST), was incorporated within the algorithm. Other professionals, such as dieticians, were consulted when specialist advice was required. The KTA facilitated the development of the algorithms, leading the meetings and eliciting the required information from the professionals to develop the algorithms.

\footnotetext{
"Take in Figure 2"
} 
Manuscript ID JHOM-May-2011-0053.R3

The "localisation" undertaken by each PCT participating in the project was facilitated by the KTA; this individual helped staff to consider the local options (provided by health services and local authorities) available to address the problems that might be identified by the assessments. Whilst this ensured that GM-SAT could be practically applied in each PCT, it doubled as an effective gap-analysis, enabling PCTs to recognise where the services they commissioned were unable to meet the need of their stroke patients.

\section{Discussion}

Work is now underway to identify and implement method(s) by which the GM-SAT can be disseminated throughout the wider NHS, both in terms of who it should be delivered by and how, and to determine the impact of 6 month post-stroke reviews on long term clinical and social outcomes and quality of life. The former will enable NHS providers and commissioners to meet the challenging demands of the National Stroke Strategy and the Accelerated Programme for Stroke Improvement, which require that 95 per cent of stroke patients are reviewed 6 months after leaving hospital.

Whilst the above project sounds reasonably straightforward it should be acknowledged that the NHS in Greater Manchester is culturally diverse and serves a number of socio-economic groupings. Furthermore, the NHS is dynamic and complex (Iles \& Sutherland, 2001), derived from many factors, the majority of which pre-date or are external to the NHS itself professional socialisation, differing needs of patients, local priorities, resource constraints, pressure groups etc. Johnson \& Scholes (1999) represented the culture of the NHS through the use of the Cultural Web which represents the 'taken for granted' attributes of an organisation. The authors believe that the involvement of a range of professionals and patients in the process of change described in this paper has helped to mitigate the potential 
effects of complexity and 'taken for granted' attributes on the development of GM-SAT. Previous research demonstrates that change programmes 'work' when they have been locally agreed but also have executive level support (Mowles et al, 2010; Bamford \& Lodge, 2006). In this case executive level support was demonstrated by local stroke commissioning and clinical leads supporting the project from the outset through their willingness to provide access to staff and resource as appropriate.

It is vital that all key stakeholders are involved in the diagnosis of the problem, as well as in the formulation of the proposed solution, using participatory techniques such as focus groups. In this change process, we have used the views of experts, including service users, to develop the GM-SAT by identifying key areas of concern, and then developing the associated management algorithms to capture and communicate this knowledge. The KTA fully engaged with stakeholders to ensure they felt their views were adequately represented and that GM-SAT (the assessment and associated management algorithms) actually did meet their needs. This has been verified by subsequent ongoing evaluation.

Staff providing services are the most knowledgeable in terms of its current delivery; with coaching they can also become the experts in the way services could be delivered more efficiently and effectively. The KTA is now working with individuals within NHS providers and commissioners and the third sector to determine, using PDSA (Plan-Do-Study-Act) cycles, effective ways of delivering the intervention. The KTA role is to supervise these cycles and to pass learning onwards to others in the process. This should facilitate more rapid transfer of information and faster cycles of change. In addition, convincing staff that change is for the benefit of the patients is vital to achieving successful change and embedding the new way of working. Clinicians and NHS providers were concerned about the impact 
Manuscript ID JHOM-May-2011-0053.R3

implementation of 6 month reviews would have in terms of time and resources - i.e. the amount of time that would be required to undertake the reviews and the volume of referrals that would be generated as a result. Using small cycles of change (incremental improvement approaches utilising PDSA on specific initiatives) and drawing on evidence from evaluation, when available, enabled this to be addressed. Some were unsure what tangible benefits a 6 month review would bring, especially the impact on patient clinical outcomes. The requirement to perform post-stroke reviews is based solely on clinical consensus, codified in the National Stroke Strategy, and not by clinical trials of reviews showing the effect on medical outcomes (Williams and Rudd, 2010). It was not possible to allay these concerns by showing evidence from trials; the key imperative was the national policy requirement. The focus on patients was the key in overcoming resistance to change; following the stakeholder workshops many of the clinical staff realised that patients had unmet needs not apparent during their interaction with a single health professional. The KTA role was vital to the spread of process change and learning across and within organisations in the development of GM-SAT.

Changes implemented within one section of healthcare can potentially have a knock-on effect on others as patient pathways tend to cross boundaries (Berwick, 2004; Iles \& Sutherland, 2001). Some of these effects can be mitigated by contextualisation. In this process, the KTA actively worked with individual PCTs and social service departments to gain multiple stakeholder perspectives so that the GM-SAT was relevant to each organisation. The authors believe that this process was helpful to PCTs, enabling them to review the services that they commission, and ensured that the PCT and social service departments were aware of any commissioning gaps. This has been shown by subsequent changes in services commissioned and, with the 6 month post-stroke review currently being a proposed requirement of the NICE 
Commissioning Outcomes Framework (National Institute for Health and Clinical Excellence, 2012), we anticipate that, following implementation, GM-SAT will continue to be used in the long-term in the new clinically-led NHS commissioning environment.

\section{Conclusion}

Any change initiative will encounter resistance within a socially organised process and the NHS is no exception to this rule (Lodge and Bamford, 2007). Some staff within the NHS have become change fatigued (Berwick, 2004) and are suspicious and resistant to change agents without considering the possibility that change could be beneficial. A change agent within the NHS must have credibility and must gain the trust of those with whom they are working. “...when programme champions play an active role in the development, spread and implementation of innovation, these processes are generally more effective..." (Greenhalgh, 2004:165). The resistance to change within this initiative included scepticism about the benefits of such a review, despite it being national policy. There was gradual acceptance through the developing profile of the policy as well as sharing of early evaluation results and the patient driven need helped dissipate resistance. The authors believe that the approach to change taken in this project made a fundamental contribution to the successful development, realisation and introduction of the GM-SAT. Ultimately, the patients were the primary focus. Implementation of the GM-SAT in routine practice would ensure that all patients and their carers receive a holistic, evidence-based 6 month stroke review that is comprehensive yet proportional to their expressed needs. While patients and their carers would like a review to focus on the post-stroke problems that are of specific concern to them, they have indicated that the comprehensive nature of the review would prompt and effectively 'give them permission' to discuss issues that they may not have raised themselves, such as post-stroke fatigue or sexual health. Early evaluation suggests that reviews using the GM-SAT take an 
Manuscript ID JHOM-May-2011-0053.R3

average of 74 minutes (range 20 to 195 minutes) to complete, which is considered by providers to be within reasonable limits for a detailed assessment of a patient following stroke. Early evaluation has also suggested that the use of simple treatment algorithms allows people with knowledge of stroke, but not necessarily clinical qualifications, to signpost service users appropriately to community services and sources of information.

Discussion with patients, carers, NHS service managers and clinicians reported that, as a result of a review, the stroke victim feels more supported in the long term. GM-SAT also has the potential to significantly improve a patient's physical, psychological and social outcomes and to optimize their quality of life. This will be explored further in future phases of work. The overall approach to change used in this project is being evaluated within the Greater Manchester CLAHRC, and its effectiveness will be assessed through projects carried out in other disease areas using the same approach. This will serve to verify (or otherwise) the success of its use in developing GM-SAT.

\section{References}

Accelerated Stroke Improvement Programme, http://www.improvement.nhs.uk/stroke/, 2010 Aiken, C and Keller, S (2009) The irrational side of change management, McKinsey Quarterly article, April 2009

Bamford, D, Forrester, P (2003) Managing planned and emergent change within an operations management environment. International Journal of Operations and Production Management, Vol.23, pp.546-564

Bamford, D R \& Daniels, S. (2005) A case study of change management effectiveness within the NHS, Journal of Change Management, Vol.5, Iss.4, pp.391-406

Bamford, D \& Lodge, A (2006), Quality Improvement and Quality Service Delivery in Radiology, in Proceedings of $11^{\text {th }}$ European Forum (BMA) on Quality Improvement in Health Care, Prague, Czech Republic

Berwick, DM, (2004), Escape Fire: Designs for the Future of Health Care, Institute for Healthcare Improvement, Jossey-Bass.

Burnes B (2009) Managing Change. 5th edn. Harlow: FT/Prentice Hall

Burns, G.R. and R.R. Paton (2005) Supported Workplace Learning: a knowledge transfer paradigm. Policy Futures in Education: Vol.3, Iss.1, pp.50-61 
Deeter-Schmelz, DR, Kennedy K (2003) Patient care teams and customer satisfaction: the role of team cohesion. Journal of Service Marketing, Vol.17, pp.666-684

Department of Health, National Stroke Strategy. London: HMSO, 2007

Farrington-Douglas J, Brooks R (2007) The Future Hospital: The Politics of Change. London: Institute for Public Policy Research. See www.ipr.org

Freeth, P (2004) Organisational Change, www.ciauk.com/resources/orgchange.htm, accessed 19/04/04.

Greenhalgh, T. (2004), How to Spread Good Ideas. A Systematic Review of the Literature on Diffusion, Dissemination and Sustainability of Innovations in Health Service Delivery and Organisation, National Co-ordinating Centre for NHS Service Delivery and Organisation R\&D, London Hackett ML, Yapa C, Paraq V and Anderson CS (2005) Frequency of depression after stroke: a systematic review of observational studies. Stroke, Vol.36, Iss. 6, pp.1330-1340.

Harvey G, Fitzgerald L, Fielden S, McBride A, Waterman H, Bamford D, Kislov R and Boaden R (2011) "The NIHR Collaboration for Leadership in Applied Health Research and Care (CLAHRC) for Greater Manchester: Combining empirical, theoretical and experiential evidence to design and evaluate a large-scale implementation strategy" Implementation Science 6:96 (doi:10.1186/1748-5908-6-96)

Harvey S, Liddell A, McMahon L. Windmill (2007) The Future of Health Care Reforms in England. London: King's Fund, June 2007. www.kingsfund.org.uk

Henderson, J., R. McAdam, and D. Leonard (2006) Reflecting on a TQM based university/industry partnership. Management Decision, Vol.44, Iss.10, pp.1422-1440 Iles, V \& Sutherland, K (2001) Managing Change in the NHS - Organisational Change: A Review for Health Care Managers, Professionals and Researchers, National Co-Ordinating Centre for NHS Service Delivery and Organisation Research \& Development, May 2001 Intercollegiate Stroke Working Party. National clinical guideline for stroke, 3rd edition. London: Royal College of Physicians, 2008.

Johnson, G \& Scholes, K (1999) Exploring Corporate Strategy, $5^{\text {th }}$ Edition, Prentice Hall Jørgensen L, Engstad T and Jacobsen BK (2005) Self-reported urinary incontinence in noninstitutionalized long-term stroke survivors: A population-based study. Archives of Physical Medicine and Rehabilitation, Vol. 86, Iss. 3, pp. 416-420.

Kitson, A.L., Rycroft-Malone, J, Harvey, G, McCormack, B, Seers, K, Titchen, A. Evaluating the successful implementation of evidence into practice using the PARIHS framework: theoretical and practical challenges (2008) Implementation Science, 3:1: p. doi:10.1186/17485908-3-1.

Langley, G.J., Nolan, K.M, Norman, C.L, Provost, L.P, Nolan, T.W (1996) The Improvement Guide. San Francisco: Jossey-Bass

Lodge, A \& Bamford, D. (2007) Health Service Improvement through Diagnostic Waiting List Management, Leadership in Health Services Journal, Vol.20, Iss.4, pp.254-265

Lodge, A. and D. Bamford (2007) Health service improvement through diagnostic waiting list management'. Leadership in Health Services, Vol.20, Iss.4, pp1751-1879

Mowles, C, van der Gaag, A, Fox, J (2010), The practice of complexity: Review, change and service improvement in an NHS department, Journal of Health Organization and Management Vol. 24, Iss.2, pp. 127-144

National Audit Office (2010). Progress in improving stroke care. London: HMSO National Audit Office, Reducing Brain Damage: Faster access to better stroke care. London: 
Manuscript ID JHOM-May-2011-0053.R3

HMSO, 2005

National Audit Office. Progress in improving stroke care. London: HMSO, 2010

National Institute for Health and Clinical Excellence. Consultation on potential COF indicators. London: NICE, 2012

Pfeffer J and Sutton RL (2006) Hard Facts Dangerous Half-Truths \& Total Nonsense:

Profiting from Evidence-Based Management. Boston, MA: Harvard Business School Press Pollock, AM, (2004), NHS plc: The Privatisation of Our Health Care, Verso, London.

Rycroft-Malone, J, Harvey, G, Seers, K, Kitson, A, McCormack, B, Titchen, A, (2004) An exploration of the factors that influence the implementation of evidence into practice, Journal of Clinical Nursing, 13: 913-924.

Truss C, Soane, E, Edwards C, Wisdom K (2006) Working life: employee attitudes and engagement. CIPD Research Report, London

Van de Port IGL, Kwakkel G, van Wijk I and Lindeman E (2006) Susceptibility to deterioration of mobility long-term after stroke: a prospective cohort study. Stroke, Vol. 37, pp. 167-171.

Walker, V \& Bamford, D (2011), An empirical investigation into health sector absenteeism, Health Services Management Research Journal, Vol.24, Iss.3, pp. 142-150

Walsh, K, Lawless, J, Moss, C, Allbon, C (2005) The development of an engagement tool for practice development. Practice Development in Health Care, Vol.4, Iss.3, pp.124-130

Williams LS and Rudd AG (2010) Advances in Health Policy and Outcomes, Stroke, Vol.41, Iss. 2 , e $77-80$ 
Figure 1. The processes involved in the development of the Greater Manchester Stroke Assessment Tool (GM-SAT)

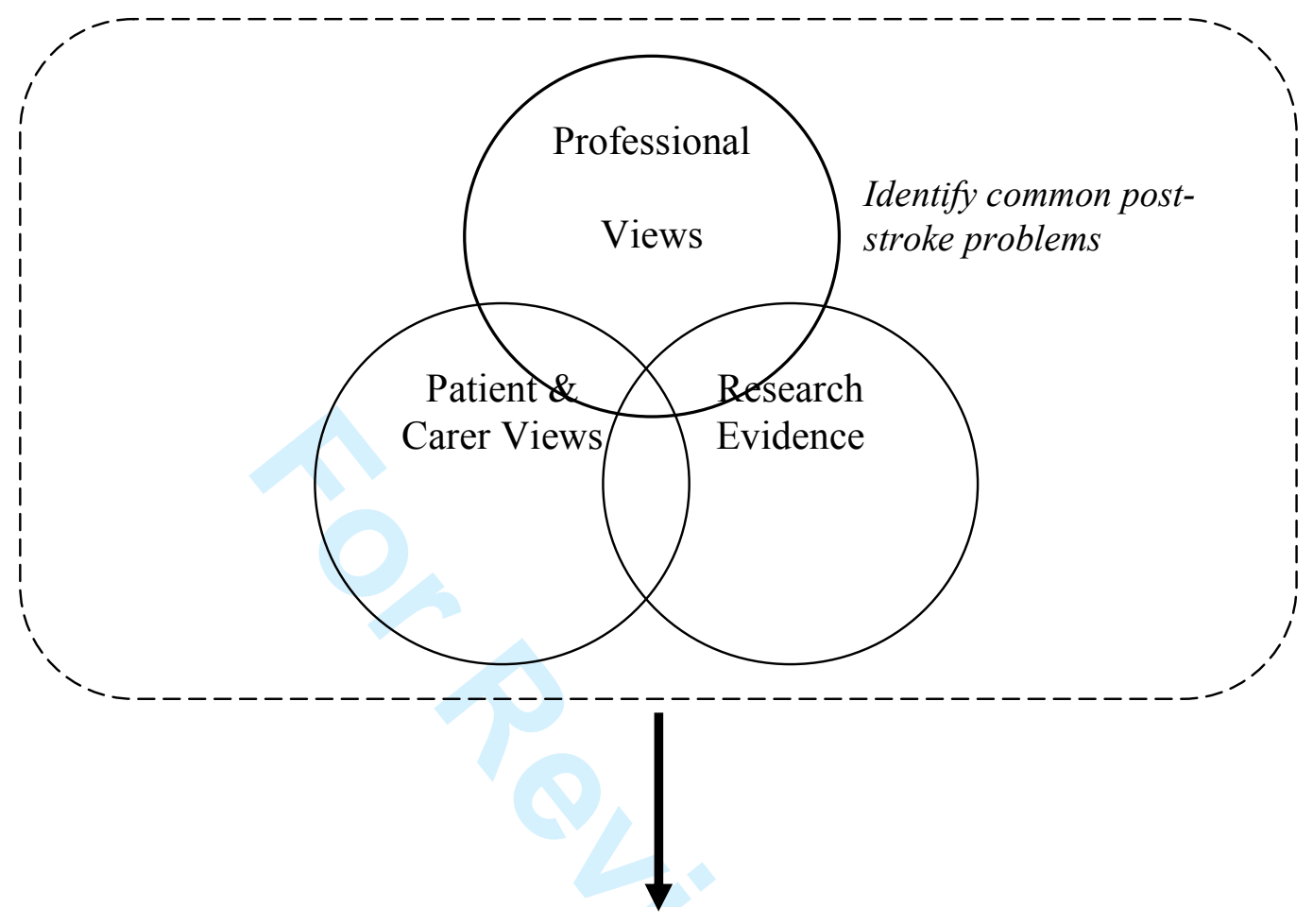

Management Algorithms

(Based on National Clinical Guidelines)

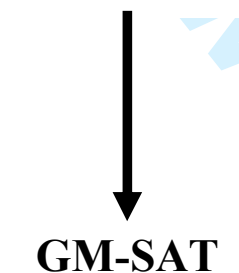

The Greater Manchester Stroke Assessment Tool 
Figure 2. Example of a management algorithm

\section{Vision}

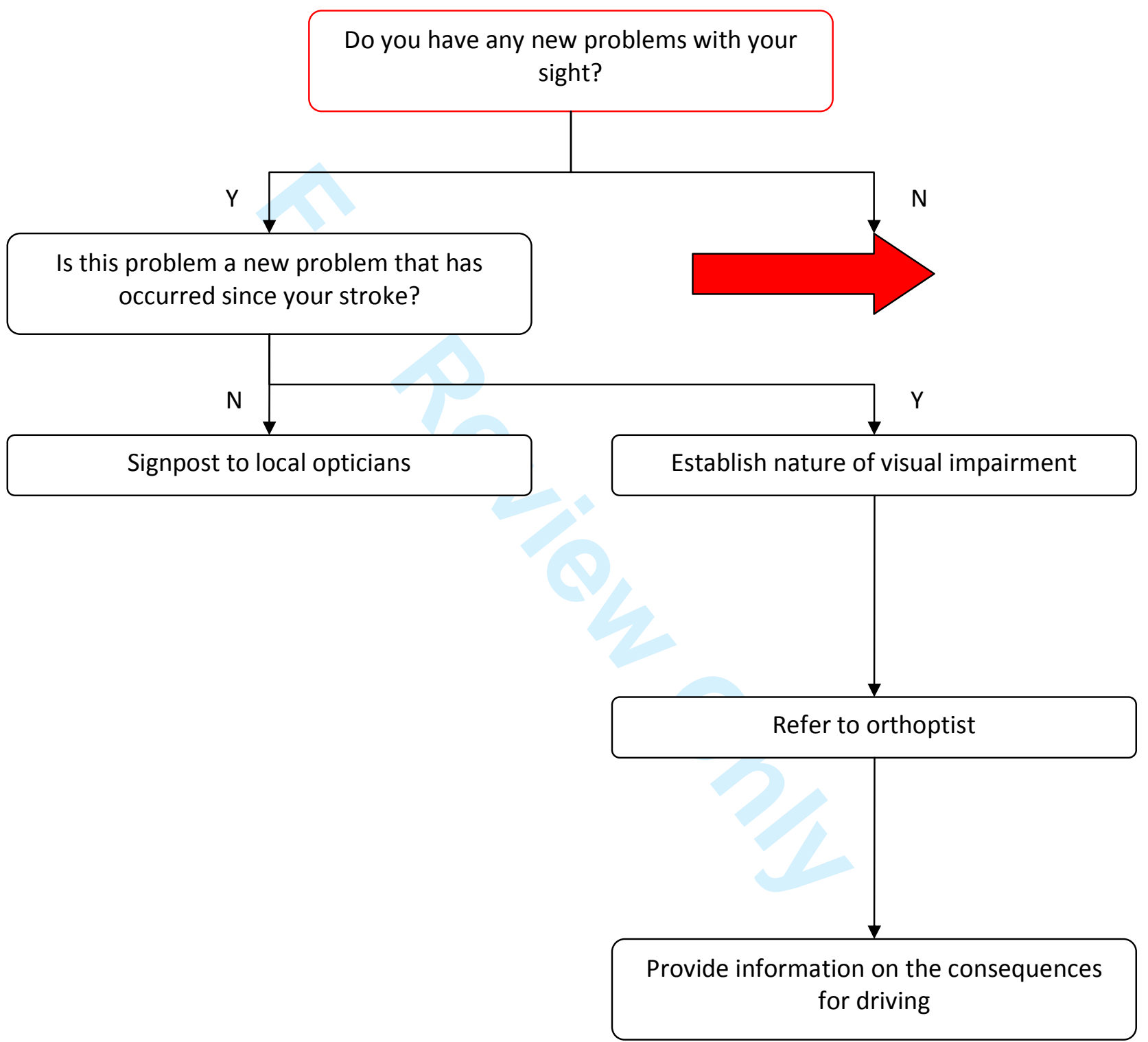


Manuscript ID JHOM-May-2011-0053.R3

Table 1. The problem areas included in the GM-SAT

\begin{tabular}{|c|c|c|c|c|c|}
\hline $\begin{array}{c}\text { Medicine } \\
\text { management }\end{array}$ & $\begin{array}{c}\text { Medicine } \\
\text { compliance }\end{array}$ & $\begin{array}{c}\text { Blood } \\
\text { pressure }\end{array}$ & $\begin{array}{c}\text { Anti- } \\
\text { thrombotic } \\
\text { therapy }\end{array}$ & Cholesterol & Diabetes \\
\hline Alcohol & Smoking & $\begin{array}{c}\text { Healthy } \\
\text { eating }\end{array}$ & Exercise & Vision & Hearing \\
\hline Communication & Swallowing & Nutrition & $\begin{array}{c}\text { Weight } \\
\text { management }\end{array}$ & Pain & Continence \\
\hline $\begin{array}{c}\text { Daily activities } \\
\text { Mobility }\end{array}$ & Falls & Mood & Anxiety & Emotionalism \\
\hline $\begin{array}{c}\text { Personality } \\
\text { changes }\end{array}$ & Sexual health & Fatigue & Sleep pattern & $\begin{array}{c}\text { Memory, } \\
\text { concentration } \\
\& \text { attention }\end{array}$ & Driving \\
\hline $\begin{array}{c}\text { Transport \& } \\
\text { Travel }\end{array}$ & $\begin{array}{c}\text { Activities \& } \\
\text { Hobbies }\end{array}$ & Work & $\begin{array}{c}\text { Money \& } \\
\text { Benefits }\end{array}$ & $\begin{array}{c}\text { House \& } \\
\text { Home }\end{array}$ & Carer Needs \\
\hline
\end{tabular}

